\title{
Analysis of a severe beyond design basis accident for the EGP-6 reactor of the Bilibino NPP. Radioactive source term determination
}

\author{
Leonid M. Parafilo ${ }^{1}$, Ruben I. Mukhamadeev ${ }^{1}$, Yury D. Baranaev ${ }^{1}$, Albert P. Suvorov ${ }^{1}$ \\ 1 State Scientific Center - Institute for Physics \& Power Engineering (SSC RF-IPPE), 1, Bondarenko sq., Obninsk, Kaluga reg., 249033 Russian \\ Federation
}

Corresponding author: Ruben I. Mukhamadeev (ben@ippe.ru)

Academic editor: Elena Artyushkova • Received 23 October 2018 Accepted 12 November 2018 Published 26 November 2018

Citation: Parafilo LM, Mukhamadeev RI, Baranaev YD, Suvorov AP (2018) Analysis of a severe beyond design basis accident for the EGP-6 reactor of the Bilibino NPP. Radioactive source term determination. Nuclear Energy and Technology 4(2): 135-142. https://doi.org/10.3897/nucet.4.30774

\begin{abstract}
Analysis was performed of dynamic phase of severe accident of the EGP-6 reactor of the Bilibino NPP, due to uncontrolled reactivity insertion initiated by withdrawal of two pare of automatic control rods with followed by full failure of reactor emergency protection system. This initial event leads to promt increasing of reactor core power up to $450 \%$ of nominal value with short period, coupled with rise of temperature of fuel, pressure and temperature of coolant. These factors lead to crisis of heat exchange with subsequent ruptures tubes of fuel assemblies and coolant blow down into graphite stack. All its lead to rise of pressure in reactor shell and damage of it, outflow of steam-water mixture through up-reactor area to ventilation system, communication corridors and reactor hall and further - to atmospheric release. Transient processes were calculated using code RELAP5/Mod3.2. It was considered stages of processes of fuel damage and evaluated dynamic of a number and degree of damaged fuel assembles. They were grouped on burn-up and for each group it was performed analysis of dynamic of damage values. Further it was considered processes of yield of fission products from damaged fuel with models, based on experimental data on yield of fission products from fuel material, used in assembles of Bilibino NPP fuel type (fuel tubes with steel cladding, where fuel material is grits of uranium dioxide in magnesium), under condition of severe accident, especially performed in SSC IPPE. Transport of fission products with steam and air up to release points was evaluated with models, based on experimental data of fission product transport through graphite stack under conditions of severe accident, also especially performed in SSC IPPE. Evaluation of source term was performed in accordance with accident dynamic and assumed modes of release for conservative and most possible approaches. It was noted good self-protection property of EGP-6 reactor under severe beyond design basis accident condition.
\end{abstract}

\section{Keywords}

Severe beyond design basis accident; heat exchange crisis; fuel damage dynamic; fission products yields; radioactive source term

* Russian text published: Izvestiya vuzov. Yadernaya Energetika (ISSN 0204-3327), 2018, n.1, 99-111. 


\section{Introduction}

Bilibino NPP (BiNPP) consists of 4 reactor blocks of EGP-6 reactor, with total electrical power equal to 48 MW and up to $100 \mathrm{GCal} / \mathrm{h}$ of heat production. Draft design of BiNPP was prepared in 1964, detailed design - in 1965. Construction of the BiNPP was begun in October 1966. The NPP was constructed and is operated in extremely complex climatic and transportation conditions of Arctic region. Upgrading systems and equipments aimed at the enhancement of reliability and safety of operation was implemented during the period of operation of power units of the BiNPP (Bilibino NPP. Unit 4 2016). Structural feature of the NPP design is single central hall with windows for all power units.

\section{Thermal hydraulic processes in the BiNPP building}

Accident with the following initiating event (IE) is postulated: uncontrolled reactivity insertion initiated by withdrawal of two pare of automatic control rods with followed by full failure of reactor emergency protection system. Analysis of the worst (and the least probable) scenario of this beyond design basis accident (in accordance with NP-001-2015, RB-001-05 2005, Deterministic Safety Analysis for Nuclear Power Plants 2009) was published in (Bilibino NPP. Unit 4 2016). Power level prior to the accident was assumed to be equal to $100 \%$. Reactor power dynamic is reflected in Fig.1. Estimation of reactor power dynamic was performed using the model of point kinetics of RELAP5/MOD3.2 code (Fletcher and Schultz, RELAP5/MOD3.2 2012).

Monotonous growth of reactor power occurs during 20 sec from the initial events and leads to reach maximum power level of $450 \%$ of rated reactor power (see Fig. 1). It results in the increase of temperature of fuel and rich

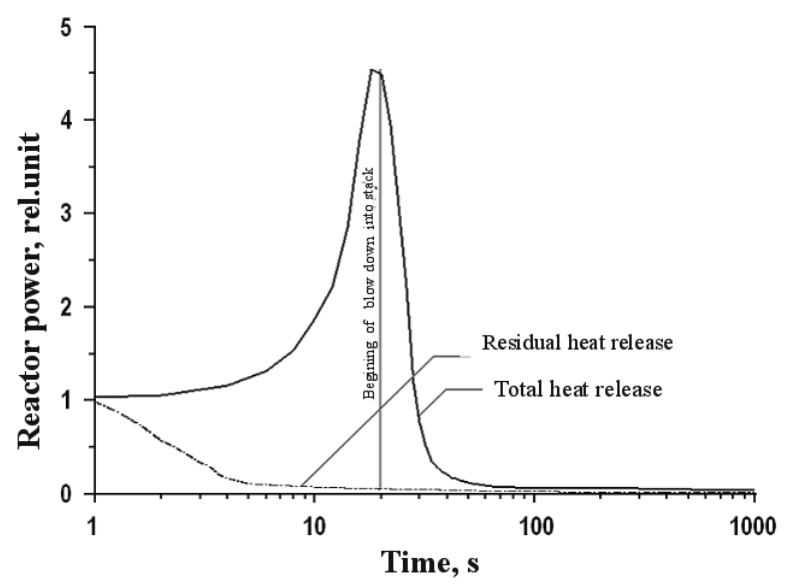

Figure 1. Dynamics of relative variation of reactor power compared with rated power to heat exchange crisis in fuel assemblies. Heat exchange crisis causes to realization of conditions for damage of internal fuel cladding with bearing coolant pressure. When temperature of coolant achieves $900^{\circ} \mathrm{C}$ under design pressure in the main circuit (MC), damage of fuel cladding in 126 fuel assemblies arise on the 20-th sec, causing blow down of coolant in the reactor stack. Max flow rate of coolant blow down rises up to $1200 \mathrm{~kg} / \mathrm{sec}$ on the 42-th sec. So total mass of coolant in MC is about 22 tons so long blow down with the rate is impossible.

Blow down of coolant in the reactor stack results in pressure rise in the reactor space (RS) and follows rupture of reactor shell on the 50-th sec with subsequent outflow of steam-water mixture in installation space, space above reactor and central hall $(\mathrm{CH})$. Steam-water mixture outflow from the RS into the installation space is significant and comparable with flow rate of blowdown from the MC. Significant level of flow rates leads to fast reduction of mass of the substance inside the volumes from which the blow down is happening and after $70 \mathrm{sec}$ from the beginning of the accident they end up to be fairly moderate which leads to the rate of outflow reduction of radioactive substances from the reactor core into the central hall of NPP building (Fig. 2).

Outflow of steam-water mixture from the installation space in the space above the reactor core takes place through the annular gap between the concrete overhead slab and the reactor top plate. Following this, outflow of steam-water mixture in the central hall $(\mathrm{CH})$ takes place causing increase of pressure, disruption of normal air exchange ensured by the ventilation systems and destruction of $\mathrm{CH}$ windows.

Outflow of steam-water mixture in the $\mathrm{CH}$ from the space above the reactor (Fig. 3) proceeds relatively evenly in time $\sim 100 \mathrm{sec}$. Total mass of outflow mixture is not more than $10 \%$ of the mass originally contained in the cooling circuit of the damaged reactor which could be explained with liquid phase for main part of coolant and separation of steam-water mixture outflow along the path to the central hall realized sequentially. There are other

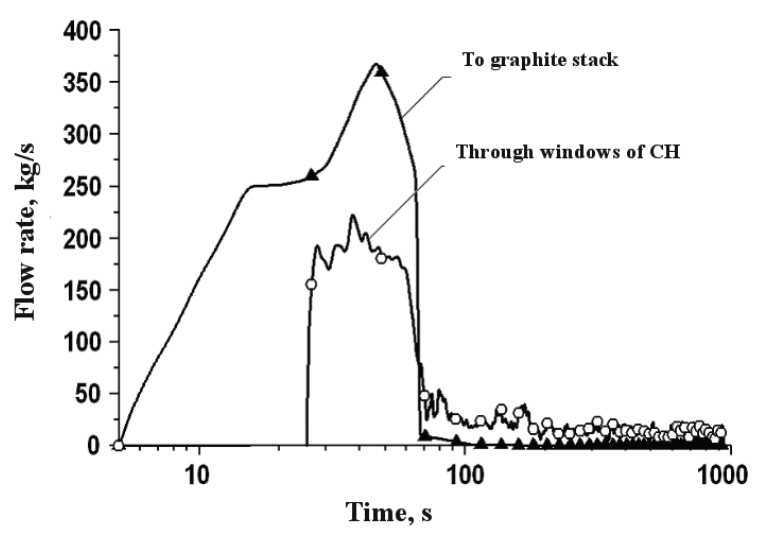

Figure 2. Flow rates of coolant blow down in the RS and through the reactor room windows 


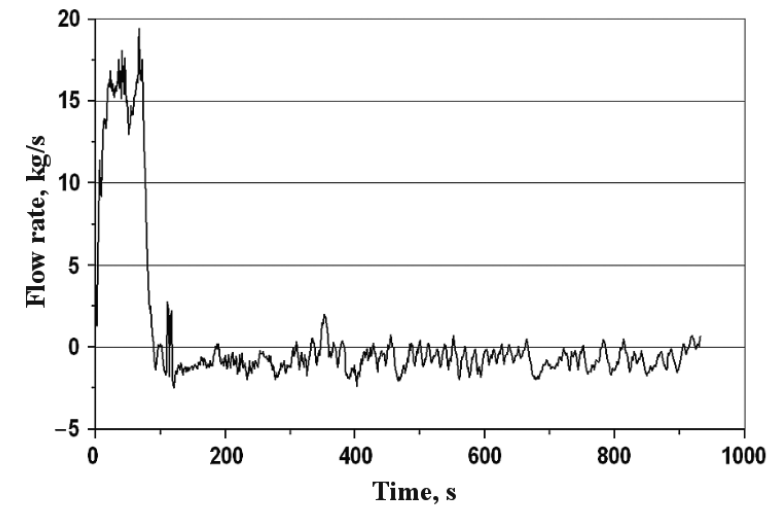

Figure 3. Flow rate of steam-water mixture from the space above the damaged reactor into the central hall

losses of this flow on main safety valve, system for localization of "wet" accident, drainage and ventilation.

Release of steam-water mixture in atmosphere corresponds to the dynamics of flow rates of outflow steam-water mixture to $\mathrm{CH}$. Flow rate of steam-water mixture from windows of the central hall is presented in Figure 4.

\section{Yield of radioactive products from damaged fuel}

The data of ( Samoylov et al. 1982, Samoylov et al. 1982a, Samoylov et al. 1996, Technical Reports Series No. 388, STI/DOC/010/388 1998, IAEA-TECDOC-1345 2003, IAEA-TECDOC-1454 2005, NF-T-2.1, STI/PUB/1445 2010), requirements (NP-082-07 2007) and results of experimental studies of behavior of reactor fuel of EGP-6 reactors implemented in 1990 - 1994 by the SSC RF-IP$\mathrm{PE}$ and published in (Baranaev et al. 1993, Baranaev et al. 1993a, Dolgov et al. 1995, 1996, Suvorov et al. 1996, 1998) were used in the investigation of processes of fuel destruction and release of radioactive fission products (RFP) from damaged fuel during the accident. They are represented in the form of three sequential stages:

Growth of power leads to growth of temperature and coolant pressure, with subsequent heat exchange crisis in some fuel assemblies. It results in the partial destruction of internal and external fuel cladding in those fuel assemblies where local temperature reaches $\sim 900^{\circ} \mathrm{C}$. At the momentum of fuel cladding destruction it were occurred instant yield of inert radioactive gases (IRG), iodine and cesium isotopes. Radioactive fission products (RFPs) are released with steam-water mixture, which serves as the carrying medium for subsequent arrival of RPFs to the reactor stack, space and later up to central hall and atmosphere.

After cessation of coolant outflow further partial destruction of fuel claddings can proceed only in those fuel assemblies (FA) where local temperature in the process of the accident could reach magnesium boiling point $\left(\sim 1100^{\circ} \mathrm{C}\right)$. Instant yield of IRG, iodine and cesium iso-

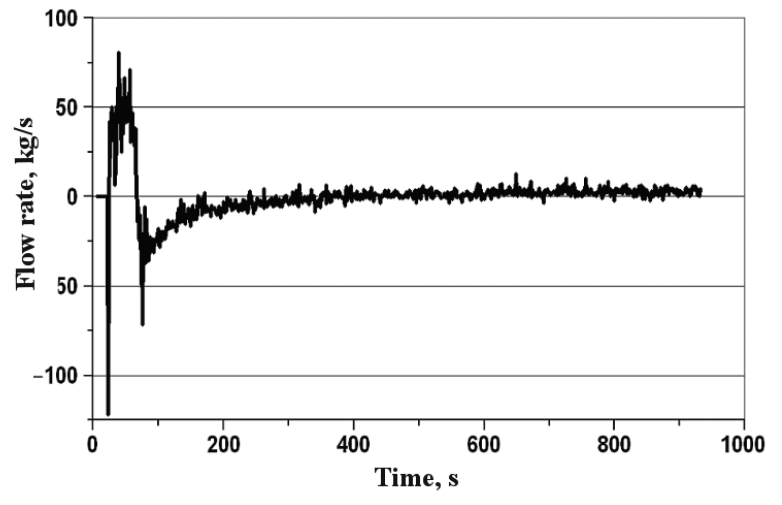

Figure 4. Flow rate of steam-water mixture through the windows of central hall

topes from contacting material of fuel matrix occurs at the moment of rupture of fuel cladding. Carrying medium for direct release of radioactive products from the reactor stack and space (and later) is not available during this phase.

Diffusive release of RFPs from heated fuel occurs in accordance with subsequent dynamic of temperature growth in those parts of destroyed fuel elements, where temperature increased above $\sim 1100^{\circ} \mathrm{C}$. Carrying medium for direct release of RFPs from reactor stack, space ans later is missing during this stage.

According to conservative estimation based on the results of experimental studies (Baranaev et al. 1993, Baranaev et al. 1993a, Dolgov et al. 1995, 1996, Suvorov et al. 1996, 1998) values of instant yield of volatile RFPs from the damaged parts of fuel during the first and second stages consists of $0.5 \%$ total activity per iodine, $0.07 \%$ total activity per cesium and $9 \%$ total activity per IRG.

Gradual increase of the yield of main RFPs from the damaged parts of fuel occurs in the process of heating uranium dioxide grit in magnesium matrix above $1100^{\circ} \mathrm{C}$, which can be described based on (Baranaev et al. 1993, Baranaev et al. 1993a, Dolgov et al. 1995, 1996, Suvorov et al. 1996, 1998) in the form of Arrhenius equation as follows:

$$
K=K_{0} \exp (-Q / R T)
$$

where $K$ is the release rate, $\mathrm{s}^{-1} ; R$ is the absolute gas constant; $T$ is the fuel temperature, $\mathrm{K}$.

Constants $Q$ and $K_{0}$ presented in Table 1 were obtained by processing of experimental data.

\section{Assessment of fuel damage during the accident}

Dynamics of accident was described in (Bilibino NPP. Unit 4 2016). On the first stage of the accident within 30 secs from the initial events (displacement of automatic control rods) growth of neutron flux power to $\sim 450 \%$ of the rated value and pressure in the MC up to $\sim 10.0$ 
Table 1. Constants for equation, which describes yields for radionuclides from fuel under hitting after cladding rupture

\begin{tabular}{|c|c|c|c|c|}
\hline Nuclide & $\mathbf{K}_{0}, \mathbf{c}^{-1}$ & Q, J/mole & Medium & Comment \\
\hline \multirow{2}{*}{ I } & 0.30 & $187.7 \times 10^{3}$ & \multirow{2}{*}{ Steam } & $1100<T<1350^{\circ} \mathrm{C}$ \\
\hline & $5.09 \times 10^{17}$ & $766.9 \times 10^{3}$ & & $T>1350^{\circ} \mathrm{C}$ \\
\hline Cs & $\begin{array}{l}7.13 \times 10^{-4} \\
1.60 \times 10^{14}\end{array}$ & $\begin{array}{l}111.8 \times 10^{3} \\
6495 \times 10^{3}\end{array}$ & Steam & $\begin{array}{c}1100<T<1350^{\circ} \mathrm{C} \\
T>1350^{\circ} \mathrm{C}\end{array}$ \\
\hline $\mathrm{Kr}, \mathrm{Xe}$ & $5.5 \times 10^{1}$ & $242.0 \times 10^{3}$ & Steam & $T>1100^{\circ} \mathrm{C}$ \\
\hline
\end{tabular}

MPa occur. Multiple ruptures of fuel accompanied with blow down of coolant into the graphite stack take place between the 30-th and 65-th secs. Complete drainage of the MC occurs by the 100-th second of accident. Further accident is accompanied with slow heating of FAs and graphite stack, followed with their subsequent cooling. Temperature dynamics for variation of max temperatures of FAs and graphite stack is presented in Figs. 5 and 6.

Dynamics for amount of damaged FAs is provided in (Bilibino NPP. Unit 4 2016) and was estimated on the basis of data of thermal engineering calculations for variations of temperatures of fuel elements and graphite (see Figs. 5 and 6). The following dynamics of FAs damages was obtained in accordance with results of calculations:

- Stage I. Partial damage of fuel cladding in 16 FAs with maximum power (eight FAs in the central part of the reactor core along the length equal to $1.45 \mathrm{~m}$ and eight FAs in the middle part along the length of $1.2 \mathrm{~m}$ ) occurs by the 35 -th second when temperature equal to $900^{\circ}$ is reached.

- Stage II. Partial damage of fuel cladding in 110 FAs with medium power (along the length of $1 \mathrm{~m}$ when temperature equal to $900^{\circ} \mathrm{C}$ is reached), occurs by the 100 -th second. Yield of RFPs from fuel are removed with coolant outflow through graphite stack into the reactor space.

- Stage III. Criterion of partial destruction of fuel rod cladding without coolant pressure, corresponded to tempera-

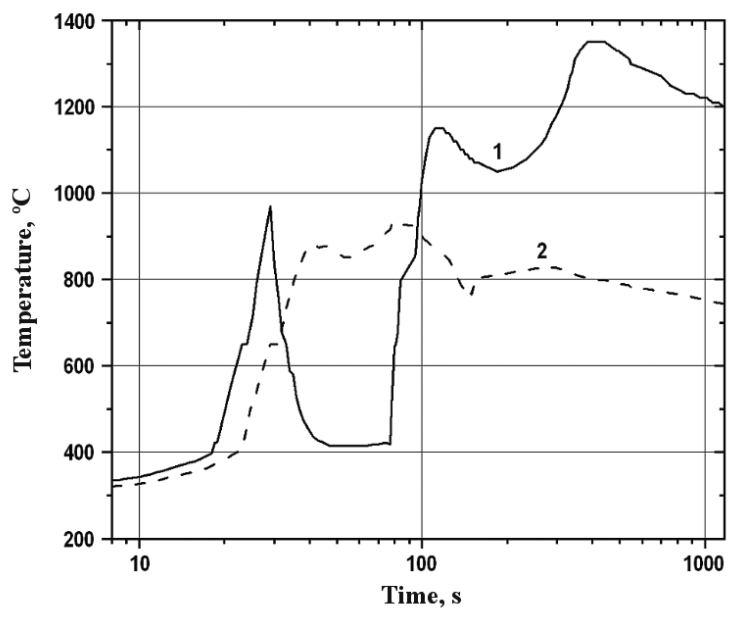

Figure 5. Dynamics of variation of maximum temperature of FAs $\left({ }^{\circ} \mathrm{C}\right)$ during beyond design basis accident: 1 - temperature of fuel rod for FA with maximum power; 2 - temperature of fuel rod for FA with medium power ture above $1100^{\circ} \mathrm{C}$ is reached after the 100 -th sec only in FAs with maximum power, which takes place during the time interval between $100 \mathrm{~s}$ and $4000 \mathrm{~s}$. Zone of fuel elements destruction increases within this interval as follows: for eight FAs with maximum power in the central part of reactor core length of damaged sections increases from 1.45 to $1.85 \mathrm{~m}$ while for eight FAs with maximum power of peripheral part of the core it increases from 1.2 to $1.55 \mathrm{~m}$. This partial destruction is accompanied with additional yield of RFPs. Diffusive yield of RFPs occurs as well due to the heating of fuel grit above $1100^{\circ} \mathrm{C}$. However, carrying medium for intensive release of RFPs from the reactor space is not present during this stage.

Estimated fraction of damaged fuel is present in Table 2 for different time moments. During estimation of fuel destruction it was conservatively accepted that temperature of all six fuel elements of FAs is equal and corresponds to the dependence for FAs with maximum and medium power presented in Figs. 5 and 6.

\section{Damaged FAs activity inventory}

Information on FA burnup is needed for estimation of source term of the accident. Distribution of FAs according to their power and burnup by the end of the time interval between fuel loading and time moment when accumulati-

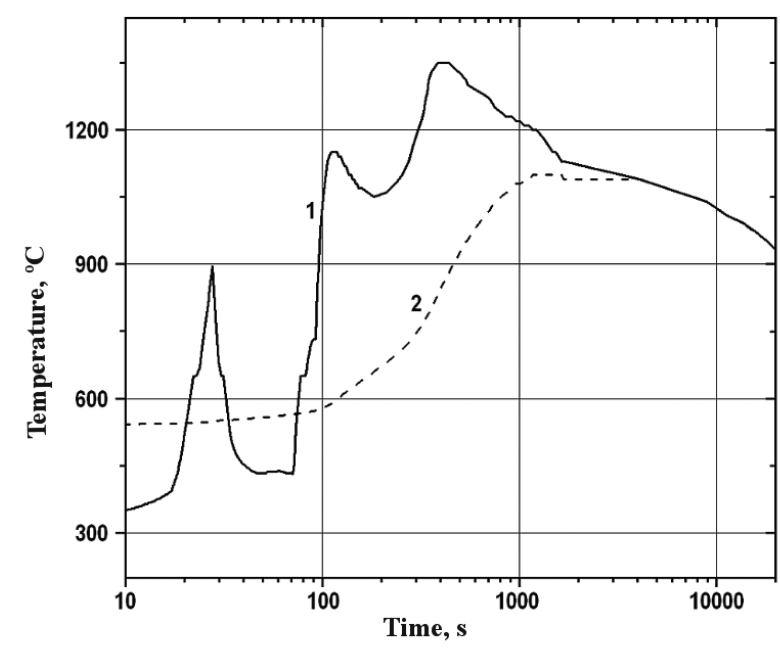

Figure 6. Time evolution of maximum temperatures of fuel rods (1) and graphite (2) for FAs with maximum power during beyond design basis accident 
Table 2. Average damaged parts of FAs during different stages of the accident

\begin{tabular}{cccc}
\hline Group of FAs & Stage I & Stage II & Stage III \\
\hline 16 FAs with maximum power & 0.40 & 0.40 & 0.57 \\
110 FAs with medium power & 0.00 & 0.33 & 0.33 \\
\hline
\end{tabular}

on of RFPs in fuel is maximum is presented in Figs 7 and 8 . It was conservatively assumed that the accident takes place specifically at that time moment.

All damaged FAs were divided into three groups according to their power and burnup. Among 16 FAs with maximum power (those to be damaged the first) 12 FAs have average burnup $\sim 60 \mathrm{MW} \times$ day/FA with power equal to $300 \mathrm{~kW} / \mathrm{FA}$ and four FAs have average burnup $\sim 157$ $\mathrm{MW} \times$ day/FA with power equal to $290 \mathrm{~kW} / \mathrm{FA} .110 \mathrm{FAs}$ of medium power which are also destroyed during the initial phases of the accident correspond to the group with average level of burnup $\sim 219 \mathrm{MW} \times$ day/FA with power equal to $227 \mathrm{~kW} / \mathrm{FA}$. Calculations were performed with code ORIGEN-2.1 (Croff 1983) taking into account calculated data from (Deen et al. 1995, Sharapov 1997) for quantitative determination of accumulation of fission products in the above three groups of FAs for different time moments after the initial event of the accident allowing correctly determining quantities of released short-lived nuclides.

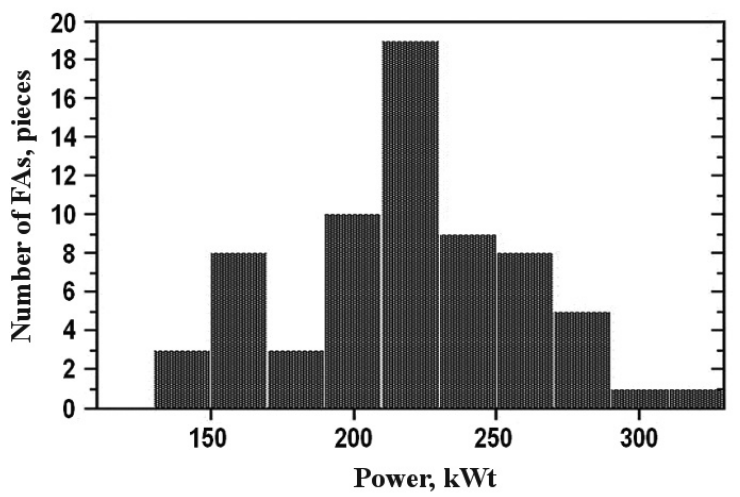

Figure 7. Histogram of FA distribution according to power in EGP-6 reactor installation

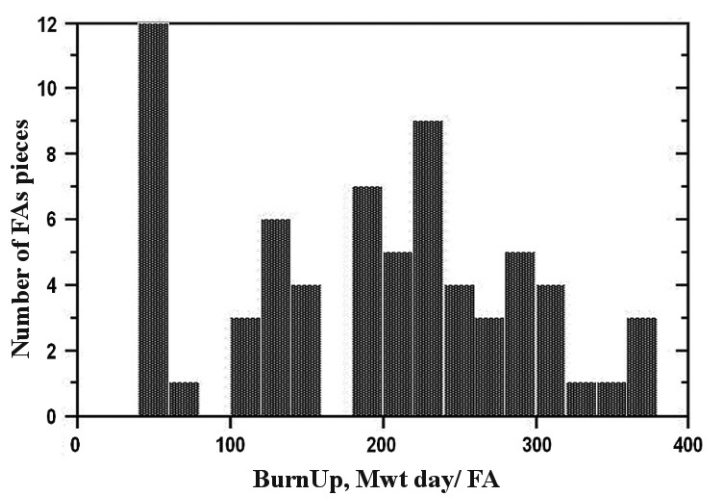

Figure 8. Histogram of FA distribution according to burnup in EGP-6 reactor installation

\section{Fission products transport through graphite stack}

Transport of RFPs through the graphite stack is accompanied with their partial sorption and secondary desorption. Coefficients of transport for RFP through the graphite stack are presented in Table 3 for the stage of coolant outflow.

Table 3. Coefficients of transport for RFP through graphite stack, \%

\begin{tabular}{lccc}
\hline \multirow{2}{*}{$\begin{array}{c}\text { Graphite stack, } \\
{ }^{\mathbf{0}} \mathbf{C}\end{array}$} & IRG & I & Cs \\
\cline { 2 - 4 } & 0.2 & 0.05 & 0.02 \\
500 & 1.7 & 0.59 & 0.25 \\
600 & 2.3 & 0.9 & 0.4 \\
700 & 3.7 & 1.9 & 1.2 \\
800 & 5.0 & 2.8 & 1.9 \\
900 & 7.7 & 5.8 & 5.2 \\
1000 & 10.5 & 8.8 & 6.6 \\
1100 & 16.0 & 13.2 & 14.0 \\
1200 & 25.0 & 20.0 & 22.0 \\
\hline
\end{tabular}

Coefficients of trapping RFPs with graphite stack (Table 4) were used for quantitative estimation of activities of different nuclides on the basis of the data of calculations for graphite stack temperature dynamic.

Table 4. Coefficients of RFP trapping with graphite stack during different time intervals, $\%$

\begin{tabular}{lcc}
\hline \multicolumn{1}{c}{ Time interval, $\mathbf{s}$} & $\mathbf{0 - 2 5 0}$ & $\mathbf{2 5 0 - \mathbf { 4 0 0 0 }}$ \\
\hline Cs & 0.34 & 0.37 \\
I & 0.54 & 0.58 \\
IRG & 1.19 & 1.21 \\
\hline
\end{tabular}

\section{Severe beyond design basis accident radioactive source term}

Release of nuclides into the reactor space (RS) was formed taking into account all the above presented data on the activity inventory for damaged fuel, yield and transfer of RFPs. Consist and activity for RFPs release into the $\mathrm{RS}$ and the dynamics of its time evolution are presented in Table 5.

The computational analysis of the accident dynamic demonstrates that approximately $7.3 \%$ of total mass of steam-water mixture, which amounts to $\sim 1215 \mathrm{~kg}$, which outflow from the RS during stages I and II, are immediately released into atmosphere through the destroyed window of the $\mathrm{CH}$. Remaining mass of steam-water mixture (16285 kg or $92.7 \%$ of total mass) is dynamically redistributed after outflow from the RS between the volumes of rooms of the plant in concordance with technological communication lines and available leaks in the structures. Following this, transported activity can be released in atmosphere through ventilation systems and later in the ventilation stack. 
Table 5. Consist and activity for RFPs release into the RS, Bq

\begin{tabular}{lccc}
\hline \multirow{2}{*}{ Nuclide } & \multicolumn{2}{c}{ Release into the RS from reactor stack for different stages of the accident, Bq } \\
\cline { 2 - 4 } & $\begin{array}{c}\text { Stage I } \\
\text { (loss of sealing) }\end{array}$ & $\begin{array}{c}\text { Stage II } \\
\text { (loss of sealing) }\end{array}$ & $\begin{array}{c}\text { Stage III } \\
\text { (heating) }\end{array}$ \\
\hline $\mathrm{Kr}-85$ & $2.2 \mathrm{E} 11$ & $4.1 \mathrm{E} 09$ & $8.5 \mathrm{E} 12$ \\
$\mathrm{Kr}-85 \mathrm{M}$ & $5.4 \mathrm{E} 12$ & $3.7 \mathrm{E} 11$ & $1.7 \mathrm{E} 13$ \\
$\mathrm{Kr}-87$ & $1.1 \mathrm{E} 13$ & $7.2 \mathrm{E} 11$ & $2.4 \mathrm{E} 13$ \\
$\mathrm{Kr}-88$ & $1.5 \mathrm{E} 13$ & $1.0 \mathrm{E} 12$ & $1.3 \mathrm{E} 13$ \\
$\mathrm{Kr}-89$ & $1.4 \mathrm{E} 13$ & $5.0 \mathrm{E} 11$ & $4.6 \mathrm{E} 03$ \\
$\mathrm{I}-131$ & $3.2 \mathrm{E} 11$ & $2.3 \mathrm{E} 10$ & $2.2 \mathrm{E} 11$ \\
$\mathrm{I}-132$ & $4.8 \mathrm{E} 11$ & $3.4 \mathrm{E} 10$ & $1.2 \mathrm{E} 12$ \\
$\mathrm{I}-133$ & $7.4 \mathrm{E} 11$ & $5.3 \mathrm{E} 10$ & $4.6 \mathrm{E} 13$ \\
$\mathrm{I}-134$ & $8.3 \mathrm{E} 11$ & $5.9 \mathrm{E} 10$ & $2.7 \mathrm{E} 9$ \\
$\mathrm{I}-135$ & $6.9 \mathrm{E} 11$ & $4.9 \mathrm{E} 10$ & $2.0 \mathrm{E} 13$ \\
Xe-131M & $1.4 \mathrm{E} 11$ & $9.5 \mathrm{E} 9$ & $7.8 \mathrm{E} 11$ \\
Xe-133 & $2.9 \mathrm{E} 13$ & $2.0 \mathrm{E} 12$ & $1.3 \mathrm{E} 12$ \\
Xe-133M & $8.7 \mathrm{E} 11$ & $5.8 \mathrm{E} 10$ & $1.4 \mathrm{E} 12$ \\
Xe-135 & $1.4 \mathrm{E} 13$ & $8.6 \mathrm{E} 11$ & $7.6 \mathrm{E} 12$ \\
Xe-135M & $5.0 \mathrm{E} 12$ & $3.3 \mathrm{E} 11$ & $2.4 \mathrm{E} 9$ \\
Xe-137 & $2.0 \mathrm{E} 13$ & $8.3 \mathrm{E} 11$ & $9.7 \mathrm{E} 9$ \\
Cs-134 & $2.7 \mathrm{E} 9$ & $2.3 \mathrm{E} 7$ & $1.1 \mathrm{E} 12$ \\
Cs-136 & $8.3 \mathrm{E} 8$ & $2.0 \mathrm{E} 7$ & $2.1 \mathrm{E} 13$ \\
Cs-137 & $4.3 \mathrm{E} 9$ & $8.1 \mathrm{E} 7$ & $5.5 \mathrm{E} 11$ \\
Cs-138 & $6.5 \mathrm{E} 10$ & $4.6 \mathrm{E} 9$ & $1.1 \mathrm{E} 12$ \\
\hline
\end{tabular}

Radiation consequences of the first two stages of the analyzed accident are determined by two releases with different physical parameters:

- Through windows of the $\mathrm{CH}$ in the aerodynamic shadow of the building with low height of the release (14 $\mathrm{m})$, low velocity $(\sim 0.1 \mathrm{~m} / \mathrm{s})$ and with elevated average temperature $\sim 55^{\circ} \mathrm{C}$ of released matter;

- Through ventilation stack along the systems of ventilation.

Significant part of steam is condensed and precipitates in the process of transport of steam-water mixture on the surfaces together with non-gaseous radionuclides contained in them. Coefficient of activity transport through the ventilation system was introduced for accounting for this fact and, as well, for the fact that ventilation system is equipped with filters. The value of this coefficient was taken to be equal about 0.1 for cesium and iodine nuclides and to 1 for IRG as the conservative estimation.

Estimated results of radioactive source term for the first two stages of the accident through the windows of the $\mathrm{CH}$ and through the ventilation stack, obtained in the assumption that activity of RFPs is uniformly spread within the coolant, are presented in Table 6.

Steam-water mixture as a carrying medium for direct transport of activity from the RS in the rooms of the plant building missed on the III stage of the accident. Nevertheless the nuclides could be transported from RS to $\mathrm{CH}$ with convective air flows. After that they can be released into environment with one of the following two paths through the destroyed windows of the $\mathrm{CH}$ and through the ventilation stack after transport through ventilation systems. The following two ultimate cases of formation for source term were examined to analyze radiation consequences for the III stage of the accident:

Table 6. Estimated results of radioactive source term for stages I and II of the beyond design basis accident, Bq

\begin{tabular}{lccccc}
\hline Nuclide & $\begin{array}{c}\text { Release through CH } \\
\text { windows }\end{array}$ & $\begin{array}{c}\text { Release through the } \\
\text { stack }\end{array}$ & Nuclide & $\begin{array}{c}\text { Release through CH } \\
\text { windows }\end{array}$ & $\begin{array}{c}\text { Release through the } \\
\text { stack }\end{array}$ \\
\hline $\mathrm{Kr}-85$ & $1.6 \mathrm{E} 10$ & $2.0 \mathrm{E} 12$ & $\mathrm{Xe}-131 \mathrm{~m}$ & $1.1 \mathrm{E} 10$ & $1.3 \mathrm{E} 11$ \\
$\mathrm{Kr}-85 \mathrm{~m}$ & $3.9 \mathrm{E} 11$ & $5.0 \mathrm{E} 12$ & $\mathrm{Xe}-133$ & $2.2 \mathrm{E} 12$ & $2.7 \mathrm{E} 13$ \\
$\mathrm{Kr}-87$ & $1.0 \mathrm{E} 13$ & $\mathrm{Xe}-133 \mathrm{M}$ & $6.3 \mathrm{E} 10$ & $8.1 \mathrm{E} 11$ \\
$\mathrm{Kr}-88$ & $7.8 \mathrm{E} 11$ & $1.4 \mathrm{E} 13$ & $\mathrm{Xe}-135$ & $9.9 \mathrm{E} 11$ & $1.3 \mathrm{E} 13$ \\
$\mathrm{Kr}-89$ & $1.1 \mathrm{E} 12$ & $1.3 \mathrm{E} 13$ & $\mathrm{Xe}-135 \mathrm{~m}$ & $3.6 \mathrm{E} 11$ & $4.6 \mathrm{E} 12$ \\
$\mathrm{I}-131$ & $1.0 \mathrm{E} 12$ & $3.0 \mathrm{E} 10$ & Xe-137 & $1.5 \mathrm{E} 12$ & $1.9 \mathrm{E} 13$ \\
$\mathrm{I}-132$ & $2.4 \mathrm{E} 10$ & $4.4 \mathrm{E} 10$ & Cs-134 & $4.0 \mathrm{E} 8$ & $2.3 \mathrm{E} 8$ \\
$\mathrm{I}-133$ & $3.6 \mathrm{E} 10$ & $6.9 \mathrm{E} 10$ & Cs-136 & $6.0 \mathrm{E} 7$ & $7.7 \mathrm{E} 7$ \\
$\mathrm{I}-134$ & $5.4 \mathrm{E} 10$ & $7.7 \mathrm{E} 10$ & Cs-137 & $3.3 \mathrm{E} 8$ & $4.0 \mathrm{E} 8$ \\
$\mathrm{I}-135$ & $6.0 \mathrm{E} 10$ & $6.4 \mathrm{E} 10$ & Cs-138 & $4.8 \mathrm{E} 9$ & $6.0 \mathrm{E} 9$ \\
\hline
\end{tabular}


Table 7. Estimated radioactive source term on the III stage of the accident, Bq

\begin{tabular}{|c|c|c|c|c|c|}
\hline Nuclide & $\begin{array}{c}\text { Release through } \mathrm{CH} \\
\text { windows }\end{array}$ & Release in the stack & Nuclide & $\begin{array}{c}\text { Release through } \mathrm{CH} \\
\text { windows }\end{array}$ & Release in the stack \\
\hline $\mathrm{Kr}-85$ & $8.5 \mathrm{E} 12$ & $8.5 \mathrm{E} 12$ & $\mathrm{Xe}-131 \mathrm{~m}$ & $7.8 \mathrm{E} 11$ & $7.8 \mathrm{E} 11$ \\
\hline $\mathrm{Kr}-85 \mathrm{~m}$ & 1.7E13 & $1.7 \mathrm{E} 13$ & Xe-133 & $1.3 \mathrm{E} 12$ & $1.3 \mathrm{E} 12$ \\
\hline $\mathrm{Kr}-87$ & 2.4E13 & 2.4E13 & $\mathrm{Xe}-133 \mathrm{~m}$ & $1.4 \mathrm{E} 12$ & $1.4 \mathrm{E} 12$ \\
\hline $\mathrm{Kr}-88$ & $1.3 \mathrm{E} 13$ & $1.3 \mathrm{E} 13$ & Xe-135 & 7.6E12 & 7.6E12 \\
\hline $\mathrm{Kr}-89$ & $4.6 \mathrm{E} 3$ & $4.6 \mathrm{E} 3$ & $\mathrm{Xe}-135 \mathrm{~m}$ & $2.4 \mathrm{E} 9$ & $2.4 \mathrm{E} 9$ \\
\hline $\mathrm{I}-131$ & 2.2E11 & 2.2E10 & Xe-137 & 9.7E9 & 9.7E9 \\
\hline $\mathrm{I}-132$ & $1.2 \mathrm{E} 12$ & $1.2 \mathrm{E} 11$ & Cs-134 & $1.1 \mathrm{E} 12$ & $1.1 \mathrm{E} 11$ \\
\hline $\mathrm{I}-133$ & $4.6 \mathrm{E} 13$ & 4.6E12 & Cs-136 & $2.1 \mathrm{E} 13$ & $2.1 \mathrm{E} 12$ \\
\hline $\mathrm{I}-134$ & $2.7 \mathrm{E} 9$ & $2.7 \mathrm{E} 8$ & Cs-137 & $5.5 \mathrm{E} 11$ & $5.5 \mathrm{E} 10$ \\
\hline I- 135 & $2.0 \mathrm{E} 13$ & $2.0 \mathrm{E} 12$ & Cs-138 & $1.1 \mathrm{E} 12$ & $1.1 \mathrm{E} 11$ \\
\hline
\end{tabular}

1. Release of all activity, which outflow from RS on the III stage of the accident (Table 7), through windows of the $\mathrm{CH}$. This assumption provides max conservative estimation for consequences of the radiation accident and is realized in the case of loss of power supply for the ventilation system of space above the reactor. However, release through the windows is not large even during the dynamic phase.

2. Release of all activity from the RS through ventilation ducts in the ventilation stack. Total coefficient of activity transport through the ventilation system is determined only with filters efficiency, and for stage III this coefficient of activity transport for Cs and I nuclides was accepted to be equal to 0.1 , and for IRG was taken to be equal to 1 .

Release in the ventilation stack for the stage III is the most probable, because flow rate for the ventilation system from the space above the reactor is $\sim 12000 \mathrm{~m}^{3} / \mathrm{h}$.

Estimated radioactive source term on the III stage of the accident are presented in Table 7.

Thus, to perform analysis of consequences of sever beyond design basis accident for public it is necessary takes into account the dynamics and scale of fuel destruction, specific features of transport for radionuclides and paths of release into the environment for different phases of the accident.

\section{Conclusion}

It war performed computational analysis for phenomenology of severe beyond design basis accident due to uncontrolled positive reactivity insertion initiated by withdrawal of two pare of automatic control rods with followed by full failure of reactor emergency protection system.

An assessment of the dynamics of fuel assemblies damage and the impact of possible ways of transporting radionuclides through the NPP premises on the formation of an accidental release was made.

Radioactive source term of the accident into the environment have been estimated on the basis of a conservative approach and for the most probable scenario of the accident.

It was demonstrated the features of the self-defense of EGP-6 reactor (trapping of RFPs with reactor stack, the operation of the ventilation system of space above the reactor) allow significantly reduce the release of activity into the environment, even in the case of a postulated sever beyond design basis accident with fuel element damage in 126 fuel assemblies.

\section{References}

- Baranaev YuD, Dolgov VV, Moseev LI, Viktorov AN (1993) Release of Fission Products from Dispersion Nuclear Fuel in Conditions of Accidents at Nuclear Icebreakers and the Bilibino NPP / The $15^{\text {th }}$ Mendeleyev Congress on General and Applied Chemistry. Obninsk Symposium. Abstracts of reports in 2 volumes, 58. [in Russian]

- Baranaev YuD, Dolgov VV, Moseev LI, Viktorov AN (1993a) Experimental determination of fission product release from the Bilibino NPP reactor fuel in conditions simulating severe accidents. Atomic Energy 74(5): 416-421. [in Russian] https://doi.org/10.1007/ BF00844625

- Bilibino NPP. Unit 4. (2016) In-depth Safety Analysis Report. JSC Concern Rosenergoatom, JSC SSC IPPE, JSC Atomenergoproekt, JSC Izhorskiye zavody. Moscow, Rosenergoatom, 4971 pp. [in Russian]

- Croff AG (1983) ORIGEN-2: A Versatile Computer Code for Calculating the Nuclide Compositions and Characteristics of Nuclear Materials, Nuclear Technolog 62: 335-352. https://doi.org/10.13182/ NT83-1

- Deen JR, Woodruff WL, Costescu CI (1995) WIMS-D/4 User Manual. Rev.0. Argonne National Laboratory and University of Illinois, ANL/RETR/TM-23, Argonne, 95 pp. http:/www.oecd-nea.org/ tools/abstract/detail/nea-0329 [accessed Sep. 21 2017].

- Deterministic Safety Analysis for Nuclear Power Plants (2009) IAEA SAFETY STANDARDS SERIES No. SSG-2, STI/PUB/1428, IAEA, Vienna, 84 pp.

- Dolgov VV, Ilyin YuV, Ryabov VV $(1995,1996)$ Results of the Bilibino NPP fuel element testing in conditions simulating an accident with complete loss of coolant and failure of all active cooldown 
channels/The $4^{\text {th }}$ Interdepartmental Conference on Reactor Material Science, 15-19 May 1995, Dimitrovgrad. Collection of Reports in 2 Volumes. Dimitrovgrad. NIIAR Publ., V. 1. Fuel and Fuel Elements of Power Reactors, 165-177. [in Russian]

- Fletcher CD, Schultz RR RELAP5/MOD3 Code Manual. NUREG/ CR-5535, INEL-95/0174, v. 2, 293 pp.

- IAEA-TECDOC-1345 (2003) Fuel Failure in Water Reactors: Causes and Mitigation (Proceedings of Technical Meeting, Bratislava, 2002), IAEA, Vienna, $165 \mathrm{pp}$.

- IAEA-TECDOC-1454 (2005) Structural Behavior of Fuel Assemblies for Water Cooled Reactors (Proc. Tech. Mtg. Cadarache, France, 2004), IAEA, Vienna, 324 pp.

- NF-T-2.1, STI/PUB/1445 (2010) Review of fuel failures in water cooled reactors. IAEA, $178 \mathrm{pp}$.

- NP-001-2015 (2015) General Provisions for Ensuring NPP Safety. Moscow. Rostekhnadzor Publ. [in Russian]

- NP-082-07 (2007) Nuclear Safety Regulations for Reactor Facilities of Nuclear Power Plants. Moscow. Rostekhnadzor Publ., 26 pp. [in Russian]

- RB-001-05 (2005) Recommendations on the Content of the In-depth Safety Analysis Report for Operated Nuclear Power Units (OUOB AS). Rostekhnadzor Publ, Moscow. [in Russian]
- RELAP5/MOD3.2 (2012) Certification Passport as Applied to Calculations for the EGP-6 Reactor. No. 317, dated 9.10.2012. Rostekhnadzor Publ., Moscow, 6 pp. [in Russian]

- Samoylov AG, Kashtanov AI, Volkova VS (1982) Dispersion Fuel Elements. Vol. 1. Materials and Technologies. Energoatomizdat Publ., Moscow, 224 pp. [in Russian]

- Samoylov AG, Kashtanov AI, Volkova VS (1982a) Dispersion Fuel Elements. Vol. 2. Design and Serviceability. Energoatomizdat Publ., Moscow, 256 pp. [in Russian]

- Samoylov AG, Volkov VS, Solonin MI (1996) Fuel Elements of Nuclear Reactors. Energoatomizdat Publ., Moscow, 400 pp. [in Russian]

- Sharapov VN (1997) Neutronic fundamentals of water-graphite reactors with tubular fuel elements. Dr. Sci. thesis, specialization 05.14.03. SCC RF-IPPE Publ., Obninsk. 75 pp. [in Russian]

- Suvorov AP, Baranaev YuD, Moseev LI, Kozmenkov YaK (1996, 1998) Experimental and Calculation Investigation of Fission Product Release from Fuel of Water Cooled Reactors on Initial Stage of Severe Accident. Report on TCM Design measures for prevention and mitigation of severe accident at advanced water-cooled reactors, 2125 October, Vienna. IAEA-TECDOC-1020, IAEA, Vienna, 27-37.

- Technical Reports Series No. 388, STI/DOC/010/388 (1998) Review of Fuel Failures in Water Cooled Reactors. IAEA, Vienna, 167 pp. 